\title{
Surgical strategy for an adult patient with a catecholamine-producing ganglioneuroblastoma and a cerebral aneurysm: a case report
}

Hiroyuki Kumata ${ }^{1 *}$ (D), Ryuichi Nishimura ${ }^{1}$, Chikashi Nakanishi ${ }^{1}$, Chihiro Inoue ${ }^{2}$, Yuta Tezuka ${ }^{3}$, Hidenori Endo ${ }^{4}$, Shigehito Miyagi ${ }^{1}$, Teiji Tominaga ${ }^{4}$, Michiaki Unno ${ }^{1}$ and Takashi Kamei ${ }^{1}$

\begin{abstract}
Background: Ganglioneuroblastomas, particularly those that produce catecholamine, are extremely rare in adults. Here, we report an interesting surgical case of an adult patient with a catecholamine-producing ganglioneuroblastomas in her adrenal gland, suspected to be a pheochromocytoma, and with a cerebral aneurysm.

Case presentation: The patient was a 73-year-old woman under treatment for hypertension. During a health check-up, a cystic retroperitoneal tumor was incidentally found in the superior pole of her right kidney. Her blood adrenaline level was slightly elevated, and her urinary adrenaline, noradrenaline, and dopamine levels were above the upper reference limits. In addition, 24-h urinary excretion of metanephrine, normetanephrine, and vanillylmandelic acid were all increased. 1231-Meta-iodobenzylguanidine scintigraphy showed an abnormal accumulation of the marker in the cyst wall. She was, therefore, diagnosed with a pheochromocytoma and scheduled for tumor resection. However, preoperatively, 8-mmdiameter cerebral aneurysm was incidentally found in her basilar artery. This required careful preoperative discussion. The aneurysm was difficult to approach and treat, and based on its position, shape, and size, the risk of rupture was low. Because hypertension is a major risk factor for aneurysmal rupture, we decided to proceed with the tumor resection. A lumbar catheter was placed to monitor the cerebral aneurysm for intraoperative rupture, and her transcranial motorevoked potential and somatosensory-evoked potentials were monitored to track her intraoperative neurological function. During surgery, we carefully monitored fluctuations in blood pressure and resected the tumor with minimal mobilization. Postoperatively, head computed tomography confirmed that there was no sign of rupture. Histopathologically, the tumor was diagnosed as a catecholamine-producing ganglioneuroblastoma. The postoperative course was good, and the patient's blood pressure improved.
\end{abstract}

Conclusions: Careful perioperative management is needed for a patient with both a catecholamine-producing tumor and cerebral aneurysm.

Keywords: Ganglioneuroblastoma, Cerebral aneurysm, Lumbar catheter

\footnotetext{
* Correspondence: hiroyuki-kumata@med.tohoku.ac.jp

1Department of Surgery, Graduate School of Medicine, Tohoku University, 1-1

Seiryou-machi, Aobaku, Sendai 980-8574, Japan

Full list of author information is available at the end of the article
} 


\section{Background}

Ganglioneuroblastomas (GNBs) are derived from neural crest cells and comprised a mixture of neuroblasts and ganglion cells [1]. Some GNBs produce catecholamines [2], making it difficult to distinguish them from paragangliomas by using catecholamine dynamics, such as the 24-h urinary excretion of catecholamines and their metabolites, or by 123I-meta-iodobenzylguanidine (123I-MIBG) scintigraphy. Surgical resection is the primary choice for both types of tumor; however, intraoperative blood pressure fluctuations present a high risk of complications, particularly in patients with abnormal hypertension. If the patient has a cerebral aneurysm, an even more careful strategy is needed. Here, we report an interesting surgical case of an adult patient with a catecholamine-producing GNB in her adrenal gland, leading us to suspect it to be a pheochromocytoma, as well as a cerebral aneurysm.

\section{Case presentation}

During a routine health check-up of a 73-year-old woman, abdominal ultrasonography incidentally revealed a retroperitoneal tumor with a maximum diameter of approximately $80 \mathrm{~mm}$ at the upper pole of her right kidney. She was admitted to our institution for examination of the tumor. The patient had been taking medication for hypertension, and her blood pressure had been maintained at $120-130 \mathrm{mmHg}$ with $20-\mathrm{mg} /$ day nifedipine and $2.5-\mathrm{mg} /$ day carvedilol. She had no notable abnormal findings in her general biochemistry, complete blood count, or the coagulation test. Various tumor markers, including carcinoembryonic antigen, carbohydrate antigen 19-9, squamous cell carcinoma-related antigen, and carbohydrate antigen 125, levels were also within normal ranges. Her blood noradrenaline and dopamine levels were within normal ranges, but her adrenaline level was elevated at $0.12 \mathrm{ng} / \mathrm{ml}$ and the 24-h urinary excretion of catecholamines and their metabolites were all increased (Table 1). The adrenal cortical hormone seemed to be within the normal range, but the 1-mg dexamethasone suppression test revealed mild autonomous cortisol secretion $(5.9 \mu \mathrm{g} /$ $\mathrm{dl})$. Contrast-enhanced computed tomography (CT) revealed a cystic retroperitoneal tumor with a maximum diameter of $88 \mathrm{~mm}$ within the right adrenal gland (Fig. 1a). The tumor included a walled nodule, revealed by its contrast effect in the early phase. The interior of the cyst was filled with a low-density fluid with no observed contrast effect. On magnetic resonance imaging (MRI), the nodule exhibited a low signal in the T1-weighted image and a high signal in the T2-weighted image. The cyst wall accumulated an abnormal level of the marker in both 123I-MIBG scintigraphy and positron emission tomography with 2-deoxy-2-[fluorine-18] fluoro-D-glucose/CT (Fig. 1b, c). From these findings, although the 24-h urinary excretion of catecholamines and their metabolites were
Table 1 Findings of catecholamines and their metabolites, and adrenocortical hormone

\begin{tabular}{|c|c|c|c|}
\hline & \multicolumn{2}{|l|}{ Value } & \multirow[t]{2}{*}{ Reference ranges } \\
\hline & Preoperative & Postoperative & \\
\hline \multicolumn{4}{|l|}{ Plasma concentration } \\
\hline Adrenaline & $0.12 \mathrm{ng} / \mathrm{ml}$ & $0.03 \mathrm{ng} / \mathrm{ml}$ & $<0.10 \mathrm{ng} / \mathrm{ml}$ \\
\hline Noradrenaline & $0.42 \mathrm{ng} / \mathrm{ml}$ & $0.37 \mathrm{ng} / \mathrm{ml}$ & $0.10-0.50 \mathrm{ng} / \mathrm{ml}$ \\
\hline Dopamine & $0.02 \mathrm{ng} / \mathrm{ml}$ & $0.02 \mathrm{ng} / \mathrm{ml}$ & $0.03 \mathrm{ng} / \mathrm{ml}$ \\
\hline Cortisol & $5.9 \mu \mathrm{g} / \mathrm{dl}$ & - & $4.5-24 \mu \mathrm{g} / \mathrm{dl}$ \\
\hline Renin & $4.1 \mathrm{ng} / \mathrm{ml} / \mathrm{h}$ & - & $0.3-5.4 \mathrm{ng} / \mathrm{ml} / \mathrm{h}$ \\
\hline Aldosterone & $11.2 \mathrm{ng} / \mathrm{dl}$ & - & $3.0-12 \mathrm{ng} / \mathrm{dl}$ \\
\hline \multicolumn{4}{|l|}{ 24-h urinary excretion } \\
\hline Adrenaline & 93.5 g/day & $24.7 \mu \mathrm{g} / \mathrm{day}$ & 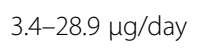 \\
\hline Noradrenaline & 269 g/day & 134 mg/day & 48.8-168 „ug/day \\
\hline Dopamine & 1600 mg/day & 780 g/day & 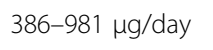 \\
\hline Metanephrine & $0.39 \mathrm{mg} / \mathrm{day}$ & 0.06 mg/day & $0.04-0.18$ mg/day \\
\hline Normetanephrine & $0.43 \mathrm{mg} / \mathrm{day}$ & 0.24 mg/day & $0.08-0.33 \mathrm{mg} / \mathrm{day}$ \\
\hline Vanillylmandelic acid & 6 mg/day & 2.8 mg/day & $1.5-4.3$ mg/day \\
\hline
\end{tabular}

not sufficiently high enough to meet the diagnostic criteria of pheochromocytoma, in consideration of image findings and clinical course, we strongly suspected that the tumor was predominantly a degenerating pheochromocytoma. The patient was scheduled to undergo tumor resection.

However, preoperative MRI incidentally revealed a cerebral aneurysm, $8 \mathrm{~mm}$ in diameter, at the junction of the basilar and superior cerebellar arteries (Fig. 1d). We, therefore, discussed with a neurosurgeon, anesthesiologist, and endocrinologist whether the retroperitoneal tumor or the cerebral aneurysm should be prioritized for treatment. Based on its size and location, the annual rupture rate of this cerebral aneurysm was estimated to be approximately $1 \%$ [3], and its deep location and large size posed a relatively high surgical risk. We, therefore, decided to proceed with the resection of the tumor, aware of the risk of an intraoperative rupture of the aneurysm subsequent to surgery-induced hypertension.

We decided to conduct more rigorous blood pressure management for the patient's surgery. Her preoperative blood pressure was managed under $120 \mathrm{mmHg}$ using $32-\mathrm{mg} /$ day doxazosin and $2.5-\mathrm{mg} /$ day carvedilol. We used epidural anesthesia for thorough analgesic management and general anesthesia centered on propofol and remifentanil, and we carefully monitored the blood pressure. After inducing general anesthesia, a lumbar catheter was placed to monitor for intraoperative rupture of the cerebral aneurysm. In addition, we used transcranial motor-evoked potential and somatosensory-evoked potential monitoring to track her intraoperative neurological function. Subsequently, the surgical procedure was performed via a right subcostal incision with upper 


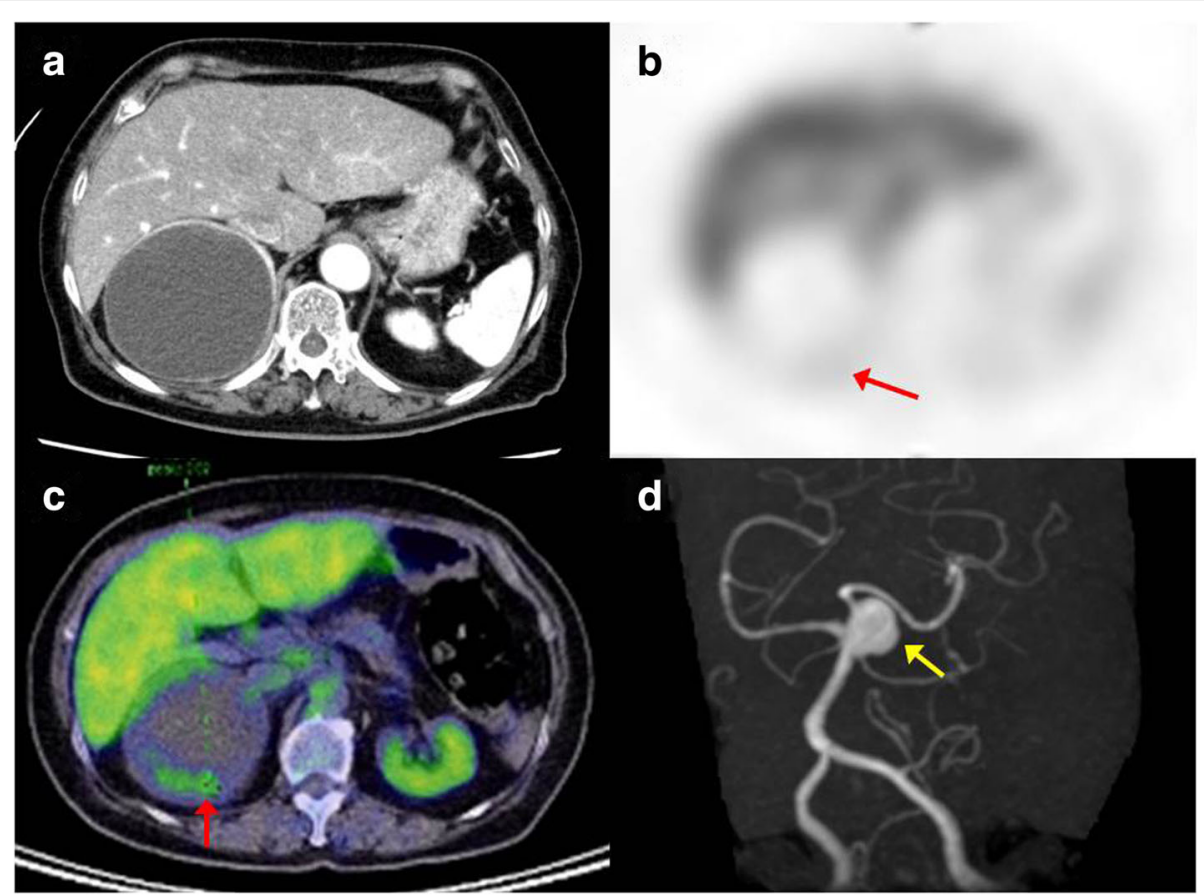

Fig. 1 Preoperative findings. a Enhanced computed tomography showed a cystic retroperitoneal tumor with a maximum diameter of $88 \mathrm{~mm}$ within the right adrenal gland. It had a walled nodule; a contrast effect was observed in the early phase along the cyst wall, including the nodule. b ${ }^{123}$ I-meta-iodobenzylguanidine scintigraphy and c positron emission tomography with 2-deoxy-2-[fluorine-18] fluoro-D-glucose/computed tomography examination, showing the abnormal accumulation of the markers along the cyst wall (red arrow). $\mathbf{d}$ Magnetic resonance angiography showing an 8-mm-diameter cerebral aneurysm at the origin of the left anterior cerebral artery (yellow arrow)

midline extension. During the surgery, we focused on fluctuations in blood pressure. Prior to full-scale tumor mobilization to prevent excessive secretion of catecholamine, we first ligated and separated the feeder arteries, consisting of three right adrenal arteries, followed by the drainage vein, consisting of a right adrenal vein. Next, we removed the tumor with minimal mobilization. The tumor had not noticeably invaded the surroundings. There was no blood outflow from the lumber catheter during the procedure. We withdrew the catheter immediately post and used head CT to confirm there had been no intracranial hemorrhage. No intraoperative blood pressure fluctuation was observed, and the cerebral aneurysm monitoring devices showed no abnormality. Complete resection (R0) was achieved by pathologically determining the negative surgical margin during surgery.

Macroscopically, the cystic tumor was approximately $100 \mathrm{~mm}$ in diameter with an interior that was almost necrotic (Fig. 2). Microscopically, two types of atypical cells with enlarged heterozygous nuclei were observed in a part of the cyst wall (Fig. 3): neuroblastic cells positive for neuron-specific enolase (Fig. 3a-c) and cells morphologically similar to ganglion cells and positive for S-100 (Fig. 3d-f). The ganglion cells were also immunohistochemically positive for tyrosine hydroxylase,
DOPA decarboxylase, dopamine-beta-hydroxylase, and phenylethanolamine- $\mathrm{N}$-methyltransferase. These two types of atypical cells were observed to form nodules without intermixing. Because no tumor cells judged as pheochromocytoma were observed, the tumor was histopathologically diagnosed as nodular GNB within the right adrenal gland. In addition, because the position of the tumor cells coincided with the site where 123I-MIBG scintigraphy showed

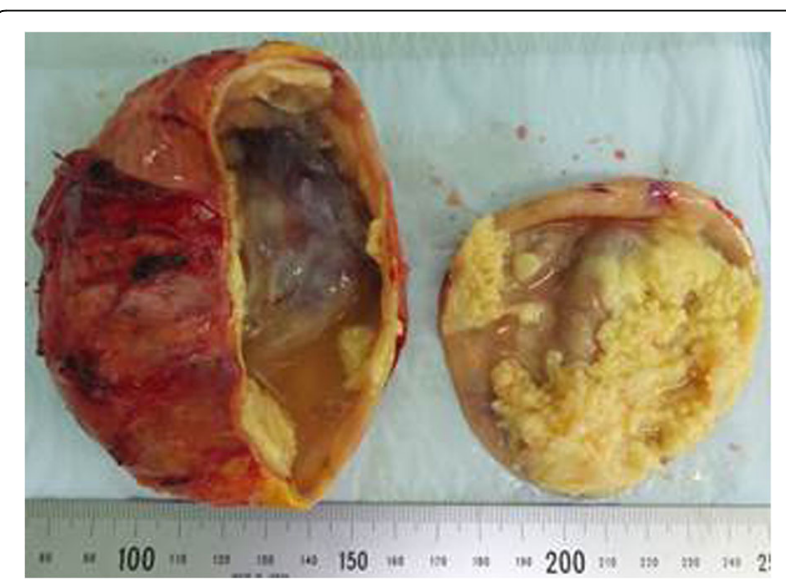

Fig. 2 Macroscopic finding. Macroscopically, the cystic tumor was approximately $100 \mathrm{~mm}$ in diameter with an interior that was almost necrotic and filled with turbid brown liquid 


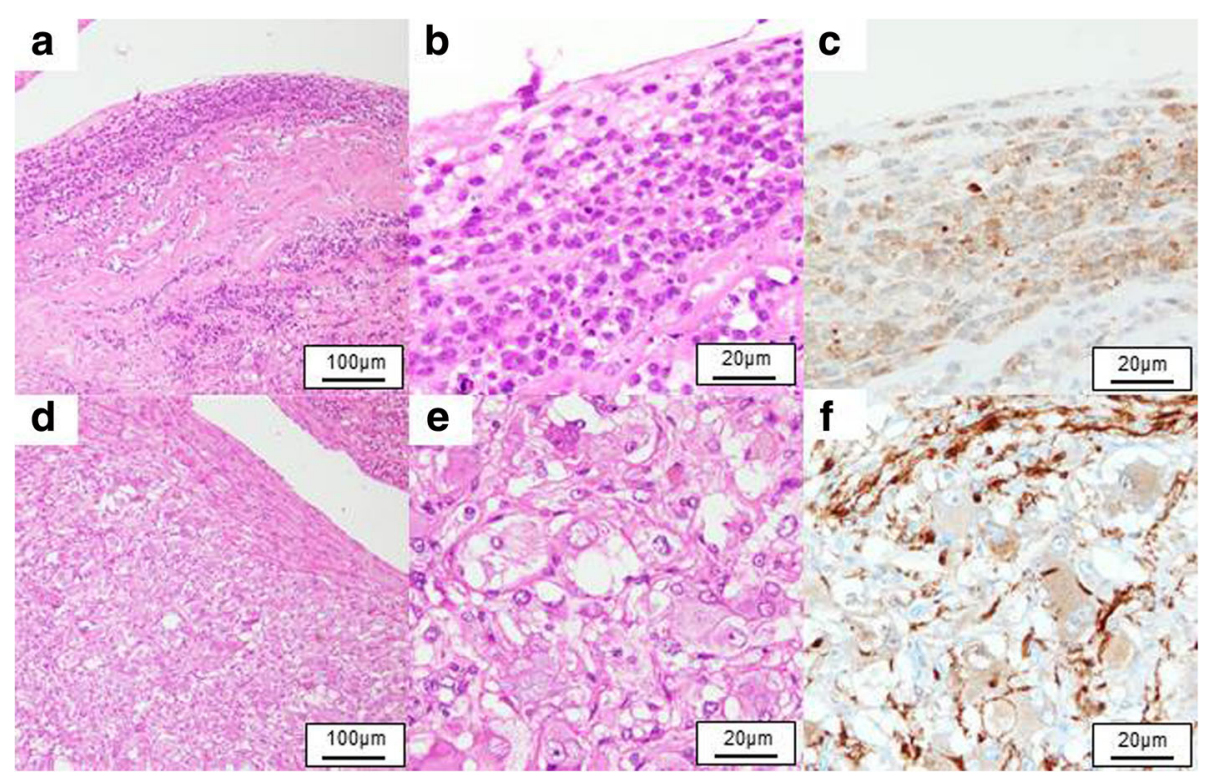

Fig. 3 Microscopic findings. Microscopically, two types of atypical cells with enlarged heterozygous nuclei are observed in a part of the cyst wall. a-c Neuroblastic cells immunohistochemically positive for neuron-specific enolase [a hematoxylin/eosin (HE), $\times 100$ magnification; b HE, $\times 400$ magnification; and $\mathbf{c}$ neuron-specific enolase, $\times 400$ magnification]. $\mathbf{d}$-f Cells morphologically similar to ganglion cells and immunohistochemically positive for S-100 (d HE, $\times 100$ magnification; e HE, $\times 400$ magnification; and (f) S-100, $\times 400$ magnification)

abnormal accumulation, the tumor was diagnosed as a catecholamine-producing GNB.

The postoperative course was good, and the patient's blood pressure after surgery was maintained under $110 \mathrm{mmHg}$ with no antihypertensive agents. She was discharged on the 7th day postoperatively. An examination after discharge confirmed that her blood and urinary catecholamine levels and metabolite excretion had returned to normal (Table 1). Three months postoperatively, no recurrence was observed.

\section{Discussion}

GNBs frequently occur in children, but their onset in adults is extremely rare [4]. Adult GNBs have a high potential to be malignant, and there have been many reports of distant metastasis to various organs, including the liver and bones [5]. Most reported adult
GNBs do not produce catecholamines; therefore, catecholamine-producing GNBs are considered to be particularly rare [6]. In our case, GNB developed in the adrenal gland. Including this case, there have been only 14 case reports in the English-language literature on GNB in adult adrenal glands [4-16], except for composite types with pheochromocytomas. Among these 14 cases, only four (including the present case) involved catecholamine-producing GNBs [6-8] (Table 2). Hypertension has been reported in approximately $10 \%$ children with neuroblastoma [2], but only one other case of an adult GNB patient with hypertension has been reported [8]. In that case and ours, the 24-h urinary excretion of catecholamines and their metabolites showed abnormally high levels, suggesting a relationship between the tumor and hypertension. It is difficult to distinguish a catecholamine-producing

Table 2 Cases of catecholamine-producing ganglioneuroblastomas

\begin{tabular}{|c|c|c|c|c|c|c|c|c|}
\hline First author (year) & Age (years) & Sex & Urinary excretion & Tumor size $(\mathrm{cm})$ & Hypertension & Treatment & Metastasis & Survival \\
\hline Cameron (1967) [6] & 58 & $\mathrm{~F}$ & $\begin{array}{l}\mathrm{Ad} \uparrow, \mathrm{NAd} \uparrow, \mathrm{Dopa} \uparrow, \\
\operatorname{VMA} \uparrow\end{array}$ & $(-)$ & $(+)$ & Surgery & $(-)$ & 3.5 years, alive \\
\hline Koizumi (1992) [5] & 47 & $\mathrm{~F}$ & $\begin{array}{l}\mathrm{Ad} \uparrow, \mathrm{NAd} \uparrow, \mathrm{Dopa} \uparrow, \\
\mathrm{M} \uparrow, \mathrm{NM} \uparrow, \mathrm{VMA} \uparrow\end{array}$ & 9 & $(-)$ & None & Bone marrow & 3 months, died \\
\hline Sargazi (2006) [4] & 45 & $\mathrm{~F}$ & Dopa $\uparrow$ & $(-)$ & $(-)$ & Surgery, ${ }^{131}$ I-MIBG & Liver, neck & 5 years, alive \\
\hline Current case & 73 & $\mathrm{~F}$ & $\begin{array}{l}\mathrm{Ad} \uparrow, \mathrm{NAd} \uparrow, \mathrm{Dopa} \uparrow \\
\mathrm{M} \uparrow, \mathrm{NM} \uparrow, \mathrm{VMA}\end{array}$ & 10 & $(+)$ & Surgery & $(-)$ & 3 months, alive \\
\hline
\end{tabular}

$F$ female, $A d$ adrenaline, NAd noradrenaline, Dopa dopamine, $M$ metanephrine, NM normetanephrine, VMA vanillylmandelic acid,

${ }^{131}$ I-MIBG ${ }^{131}$ I-meta-iodobenzylguanidine 
GNB complicated with hypertension from a pheochromocytoma based on catecholamine dynamics, such as the 24-h urinary excretion of catecholamines and their metabolites, or 123I-MIBG scintigraphy. We, therefore, assumed that the tumor was a pheochromocytoma preoperatively. However, because both pheochromocytomas and GNBs are classified as malignant tumors, it was appropriate to resect the tumor.

It was also noteworthy that our case had a cerebral aneurysm. A catecholamine-producing tumor with a cerebral aneurysm requires much more cautious management, but there is no definite consensus over management because of limited reports. A search of PubMed found no previous reports of GNB with a cerebral aneurysm, although there have been five reported cases of pheochromocytoma with cerebral aneurysms [17-21]. In four of these cases, treatment of the tumor preceded the treatment of the cerebral aneurysm [17-20], even though in all four cases, the risk of rupture was very high or there was a history of rupture. One of these four cases developed cerebral infarction during the cerebral aneurysm surgery. In the fifth case, treatment for the pheochromocytoma proceeded because of the low risk of rupture [21]. In all of these cases, the focus during surgery was only on fluctuations in blood pressure. In the present case, we thoroughly monitored for a potential rupture using an intraoperative lumbar catheter, monitored somatosensory and motor-evoked potentials to track neurological function, and performed a head CT immediately after surgery. Even though the risk of spontaneous rupture of the cerebral aneurysm was low, the intraoperative blood pressure fluctuation owing to the catecholamine-producing tumor had the potential to affect the status of the aneurysm. If any of these intraoperative monitoring processes suggested an aneurysmal rupture, we would have performed an immediate craniotomy to repair it. If the tumor surgery was in its final stage, we would have performed a craniotomy after completing the resection; conversely, if the feeding arteries had not been treated and the tumor surgery was still at an early stage, we would have given priority to the craniotomy.

For catecholamine-producing tumors with a cerebral aneurysm, whether the tumor is pheochromocytoma or GNB, careful consideration should be given to the order in which the treatments should take place, taking into consideration the risk of rupture and the possibility of malignancy. Our strategy for this catecholamine-producing tumor with cerebral aneurysm may be helpful in the treatment of similar cases in the future.

\section{Conclusions}

We reported here the case of an adult patient who developed an extremely rare catecholamine-producing
GNB with a cerebral aneurysm. Such a case required careful consideration of the order in which the tumor and cerebral aneurysm should be treated. During tumor resection, careful perioperative management was important. Further similar cases should be accumulated to establish a consensus on the treatment strategy.

\section{Abbreviations}

CT: Computed tomography; GNB: Ganglioneuroblastoma; MIBG: Metaiodobenzylguanidine; MRI: Magnetic resonance imaging

\section{Availability of data and materials}

The datasets used during the current report are available from the corresponding author on reasonable request.

\section{Authors' contributions}

$H K, R N$, and CN performed the surgery. HK, TU, KS, WN, and YH managed the perioperative course. $\mathrm{Cl}$ is a pathologist who participated in the diagnosis of ganglioneuroblastoma. YT is an endocrinologist who participated in the preoperative diagnosis and control of blood pressure. HE is a brain surgeon who diagnosed cerebral aneurysm and inserted the lumbar catheter. HK, RN, $C N, Y T, T U, K S, W N, Y H$, and HE participated in discussion. SM, TT, MU, and TK supervised the patient treatment. TK and RN prepared the manuscript. CN supervised the writing of the manuscript. All authors read and approved the final manuscript.

\section{Ethics approval and consent to participate}

The present study was conducted in accordance with the ethical standards of our institution.

\section{Consent for publication}

Written informed consent was obtained from the patient for publication of this case report and the accompanying images. A copy of the consent document is available for review by the editor-in-chief of this journal.

\section{Competing interests}

The authors declare that they have no competing interests.

\section{Publisher's Note}

Springer Nature remains neutral with regard to jurisdictional claims in published maps and institutional affiliations.

\section{Author details}

${ }^{1}$ Department of Surgery, Graduate School of Medicine, Tohoku University, 1-1 Seiryou-machi, Aobaku, Sendai 980-8574, Japan. ${ }^{2}$ Department of Pathology, Graduate School of Medicine, Tohoku University, 1-1 Seiryou-machi, Aobaku, Sendai 980-8574, Japan. ${ }^{3}$ Division of Nephrology, Endocrinology and Vascular Medicine Tohoku University Graduate School of Medicine, 1-1 Seiryou-machi, Aobaku, Sendai 980-8574, Japan. ${ }^{4}$ Department of Neurosurgery, Tohoku University Graduate School of Medicine, 1-1 Seiryou-machi, Aobaku, Sendai 980-8574, Japan

Received: 18 April 2018 Accepted: 12 September 2018

Published online: 17 September 2018

References

1. Lam AK. Update on adrenal tumours in 2017 World Health Organization (WHO) of Endocrine Tumours. Endocr Pathol. 2017;28:213-27.

2. Madre C, Orbach D, Baudouin V, Brisse H, Bessa F, Schleiermacher G, et al. Hypertension in childhood cancer: a frequent complication of certain tumor sites. J Pediatr Hematol Oncol. 2006;28:659-64.

3. Morita A, Kirino T, Hashi K, Aoki N, Fukuhara S, Hashimoto N, et al. The natural course of unruptured cerebral aneurysms in a Japanese cohort. N Engl J Med. 2012;366:2474-82.

4. Bolzacchini E, Martinelli B, Pinotti G. Adult onset of ganglioneuroblastoma of the adrenal gland: case report and review of the literature. Surg Case Rep. 2015;1:79. 
5. Koike K, lihara M, Kanbe M, Omi Y, Aiba M, Obara T. Adult-type ganglioneuroblastoma in the adrenal gland treated by a laparoscopic resection: report of a case. Surg Today. 2003;33:785-90.

6. Sargazi M, Smith ML, Worth RC, Roberts NB. A rare ganglioneuroblastoma secreting dopamine and the value of its measurement in diagnosis and prognosis. Ann Clin Biochem. 2006:43:73-6.

7. Koizumi T, Kanbayashi T, Ichiyoshi T, Nakamura M, Moriyama S. Ganglioneuroblastoma with disseminated bone marrow infiltration in an adult. Intern Med. 1992;31:1322-4

8. Cameron DG, Warner HA, Szabo AJ. Chronic diarrhea in an adult with hypokalemic nephropathy and osteomalacia due to a functioning ganglioneuroblastoma. Trans Am Climatol Clin Assoc. 1967;78:205-17.

9. Hiroshige K, Sonoda S, Fujita M, Takasugi M, Kuroiwa A, Inatomi H. Primary adrenal ganglioneuroblastoma in an adult. Intern Med. 1995;34:1168-73.

10. Mehta N, Tripathi RP, Popli MB, Nijhawan VS. Bilateral intraabdominal ganglioneuroblastoma in an adult. Br J Radiol. 1997;70:96-8.

11. Leavitt JR, Harold DL, Robinson RB. Adrenal ganglioneuroma: a familial case. Urology. 2000;56:508

12. Slapa RZ, Jakubowski W, Kasperlik-Zaluska AA, Szopinski K, Debski R, Samsel $M$, et al. Adrenal ganglioneuroblastoma in pregnant woman: diagnosis with three-dimensional ultrasound. Eur Radiol. 2002;12:S121-6.

13. Gunlusoy B, Arslan M, Selek E, Sural S, Ayder AR. A case report: adrenal ganglioneuroblastoma in a 59-year old man. Int Urol Nephrol. 2004;36:481-3.

14. Mizuno S, lida T, Fujita S. Adult-onset adrenal ganglioneuroblastoma - bone metastasis two years after surgery: report of a case. Surg Today. 2010;40:482-6.

15. Lonie J, Boles R, Boldery J. Adrenal ganglioneuroblastoma in an adult. ANZ J Surg. 2017. https://doi.org/10.1111/ans.14157.

16. Qiu W, Li T, Sun XD, Lv GY. Onset of adrenal ganglioneuroblastoma in an adult after delivery. Ann Surg Treat Res. 2015;89:220-3.

17. Browne EF, Meyer JS. Pheochromocytoma with rupture of an intracranial aneurysm: report of a case. N Engl J Med. 1952;247:671-2.

18. Sahin A, Ercelen O, Aypar U, Erbengi A. Cerebral aneurysm surgery in a patient with phaeochromocytoma. Eur J Anaesthesiol. 1998;15:367-9.

19. DeSouza TG, Berlad L, Shapiro K, Walsh C, Saenger P, Shinnar S. Pheochromocytoma and multiple intracerebral aneurysms. J Pediatr. 1986; 108:947-9.

20. Bembo SA, Elimian A, Waltzer W, Carlson HE. Pheochromocytoma in a pregnant woman with a history of intracerebral aneurysms. Am J Med Sci. 2005:329:317-9.

21. Jha AN, Lye RH. Transient hemiparesis--a cautionary tale: coexistence of phaeochromocytoma and intracranial aneurysm. J Neurol Neurosurg Psychiatry. 1985;48:188-9.

\section{Submit your manuscript to a SpringerOpen ${ }^{\circ}$ journal and benefit from:}

- Convenient online submission

- Rigorous peer review

- Open access: articles freely available online

- High visibility within the field

- Retaining the copyright to your article

Submit your next manuscript at $\boldsymbol{\nabla}$ springeropen.com 